\title{
The Dynamics of Automobile Expenditures (preliminary) ${ }^{*}$
}

\author{
Adam Copeland \\ Bureau of Economic Analysis ${ }^{\dagger}$
}

February 15, 2008

\begin{abstract}
This paper presents a dynamic demand model for light motor vehicles. Consumers solve an optimal stopping problem to decide if they want a new automobile and when in the model year to purchase it. This dynamic approach builds upon the previous, static, analysis of this market, by allowing us to determine how the mix of heterogeneous consumers evolves over the model year and to measure consumers' substitution patterns across products and time. We find there is little temporal substitution in the motor vehicle market for small price changes, but large amounts of temporal substitution for large price changes. We illustrate this asymmetric temporal response through a series of counterfactuals.
\end{abstract}

Keywords: price discrimination, discrete-choice demand estimation, automobiles JEL classification: D12, C61, L62

\footnotetext{
*I would like to thank Ana Aizcorbe and Liran Einav for their comments and suggestions. The views expressed herein are my own and not necessarily those of the Bureau of Economic Analysis or the US Department of Commerce.

${ }^{\dagger}$ U.S. Department of Commerce, Bureau of Economic Analysis, Office of the Chief Statistician BE40, Washington, DC 20230; phone: (202) 606-9948; e-mail: adam.copeland@gmail.com; webpage: http://www.copeland.marginalq.com
} 


\section{Introduction}

The conventional wisdom in the U.S. motor vehicle industry is that consumers "time" their purchase decisions. Hence, after a large upswing in monthly sales, analysts commonly forecast a sharp downswing, claiming that a significant part of last month's sales jump was the result of temporal substitution. Indeed, the monthly time series of the percent change in aggregate light motor vehicle sales (see figure 2) looks like a jagged saw, where large positive increases in sales are followed by large decreases. ${ }^{1}$

Further suggestive evidence that temporal substitution plays a substantial role in the motor vehicle market is the steady fall in prices over the model year. Every fall, automakers introduce a new vintage of their product line. Prices for these vehicles are then steadily cut each month at an average annual rate of 9 percent. $^{2}$ While several factors may cause automakers to adopt this pricing strategy, a leading possibility is that firms are taking advantage of heterogeneous consumers to temporally price discriminate. Supporting this hypothesis, Aizcorbe, Bridgman, and Nalewaik (2007) show that the average income of new vehicle purchasers falls 10 to 15 percent over the model year.

Measuring consumers' willingness to substitute across time is central to understanding both automakers' pricing strategies and the volatility of sales within the US light vehicle market. There is little formal work that quantifies to what degree the movement in new automobile expenditures is explained by new consumers entering the market, or by existing consumers changing the timing of their purchases. Hence understanding consumer demand dynamics improves our understanding of this complex industry, leading to improvements, among other things, in forecasts of automobile expenditures and valuation of automobile inventories, issues which are important for both industry-level studies and aggregate-level analysis of the national accounts.

Using recently developed empirical techniques, we formally quantify the degree to which temporal substitution plays a role in the new light motor vehicle market. To accomplish this, we construct and estimate a dynamic demand model of the automobile market. We assume that

\footnotetext{
${ }^{1}$ Light motor vehicles are those vehicles purchased by households (e.g. cars, pickups, SUVs). We use the terms automobile and light motor vehicle interchangeably in this paper.

${ }^{2}$ See Copeland, Dunn, and Hall (2006) for details on this and other stylized facts of the U.S. automobile industry.
} 
all potential consumers show up in the market for new vehicles at the beginning of the model year. Consumers are heterogeneous in income and in their tastes for vehicle characteristics and have rational expectations about future prices. Consumers solve an optimal stopping problem, deciding both if they want to purchase a new vehicle and when in the model year to purchase it. Conditional on deciding to purchase, the tradeoff a consumer faces is to buy and immediately enjoy a new vehicle, or to wait and purchase that vehicle in the future at a lower price. Hence, the value of motor vehicle services relative to other goods along with the expectation of future prices will determine the significance of temporal substitution.

Our estimation methodology is a variant of that proposed by Gowrisankaran and Rysman (2006). We use their technique of nesting the discrete choice methodology laid out in Berry, Levinsohn, and Pakes (1995), henceforth BLP, within an optimal stopping problem (Rust (1987)). Our GMM estimator is constructed using both the orthogonality conditions based on the vector of vehicles' unobserved characteristics and the average income of new vehicle purchasers. Given a guess of the model's parameters and of consumers' option values, we use the contraction mapping algorithm described in Berry (1994) to solve for products' unobserved characteristics. These steps generate values of the mean utility of each vehicle over the model year, which we then use to update the value of consumers' option values. We then repeat the contraction mapping algorithm described above and generate new vectors of unobserved characteristics and new values of the mean utility of vehicles. We cycle through this loop until consumer's option values and the mean utility values are consistent with one another. We then compute the value of the GMM loss function. Using this technique, we employ a standard simplex search algorithm to find the vector of parameters that minimize the loss function.

Two features of the data allow us to measure consumers' responsiveness to price within a dynamic setting. First, by focusing on the timing of purchases within the model year, we take advantage of a peculiarity of the automobile market whereby firms simultaneously introduce new vintages of their products every fall. ${ }^{3}$ This provides a 12 month window where we observe consumers facing the same choice set over time, but with varying prices. As such, the timing of consumers' purchases cleanly reflects the trade-off of immediately enjoying a new vehicle versus waiting to purchase the same vehicle later at a lower price. Second, we merge the

\footnotetext{
${ }^{3}$ Occasionally firms introduce new vintages at other times of the year, but these are unusual events and these vehicles account for a tiny portion of the market.
} 
price and sales data with demographic information. Specifically, we observe the mean income of new vehicle purchasers over the model year (the income data are taken from Aizcorbe, Bridgman, and Nalewaik (2007)). This income data play a crucial role in quantifying how large of a role households' sensitivity to price explains the time-series of prices and sales of automobiles, versus alternative theories such as an exogenous fall in motor vehicle utility over the model year.

The model is able to closely match the decline in average new vehicle purchasers' income. Further, we are able to precisely estimate most of the model's parameters. We find that consumers are quite heterogenous in their tastes for motor vehicle characteristics and fairly sensitive to prices. To illustrate how consumers react to price changes, we present 3 counterfactuals. Oddly, we find that consumers' temporal response to price to be kinked. For small changes to price, for example a single model goes on sale for one month, there is little to no temporal substitution and a large cross-sectional response. For large changes in price, for example all of a manufacturer's products are placed on sale for one month, there is a tremendous temporal response that complete outstrips the cross-sectional effect. We do not yet fully understand the economic forces behind this result, and so more work needs to be done to verify these results. We believe the main reason behind this asymmetric temporal response lies in our use of logit error terms in consumers' indirect utility functions. We aim to explore this claim shortly by estimating a pure characteristic model (see Bajari and Benkard (2005) and Berry and Pakes (forthcoming)), one without the logit error term.

In the literature, there are a number of different explanations behind falling prices. Stokey (1979) analyzes when falling prices are profitable for a price-setting firm and determines that, among other assumptions, heterogenous consumers and production capacity restraints, features of the automobile market, are sufficient conditions. ${ }^{4}$ Our empirical model of consumer demand shares features with this paper, including the assumptions that consumers are heterogenous and enter the market at the same time. Conlisk, Gerstner, and Sobel (1984) and Sobel (1991) study the pricing strategies of a durable goods monopolist with constant unit cost who faces an inflow of consumers. Our paper differs from these two works because we assume all households enter the market in the first period. We believe this is a more appropriate assumption on consumer behavior given our focus on the short run problem of purchasing

\footnotetext{
${ }^{4}$ BLP demonstrates that consumer heterogeneity is significant feature of the automobile market. Likewise, Hall (2000) shows that automobiles manufacturers face a number of constraints that limit capacity.
} 
a new vehicle within the model year. Finally, Pashigian, Bowen, and Gould (1995) advance the hypothesis that automobile prices decline over the model year because part of a vehicle's value is fashion. As with other fashionable goods, this fashion component declines in value the longer a product is sold. In our empirical specification, we allow for a trend in utility over the automotive model-year, which, if it declines, can be interpreted as fall in a vehicle's fashion value over its product life.

Alongside the theoretical literature, there are a number of empirical studies seeking to quantify the significance of consumer's ability to temporally substitute on firms' pricing strategies. This paper is part of a growing body of work that examines infrequently purchased durable goods which exhibit falling prices over the product cycle. Within this group, Carranza (2003), Carranza (2006), Song and Chintagunta (2003), Gordon (2006) and Nair (2005) are recent works that, relative to the current paper, examine different products (cameras, video game consoles, and computer processors) and use a variety of different empirical methods. ${ }^{5}$ Our paper is closest to Gowrisankaran and Rysman (2006), who lay out a new method for estimating dynamic demand models and apply it to the DVD industry. ${ }^{6}$ A main difference in our approaches lies in how we compute consumers' option values (i.e. consumers' expectations about the value of purchasing a good in the future). Following Melnikov (2000), Gowrisankaran and Rysman (2006) follow a reduced form approach to approximate consumers' option values. Further, they allow households to purchase multiple times over the sample. In contrast, we eschew the reduced form approximation and assume consumers have perfect foresight, as well as restrict households to a single purchase. In large part, the differences in our approach are derived from the fact that Gowrisankaran and Rysman (2006) considers a more general setting where both prices and the choice set vary from period to period. We, on the other hand, take advantage of the well-defined model-year for automobiles, and observe consumer behavior when facing varying prices, but a constant choice set.

Our paper complements an existing literature that focuses on frequently-purchased durable goods. There are a number of studies that focus on the high/low pricing strategies often used

\footnotetext{
${ }^{5}$ Gowrisankaran and Rysman (2006) provides a detailed comparison of the different methods used in these papers.

${ }^{6}$ Schiraldi (2006) extends Gowrisankaran and Rysman (2006) to include transaction costs. In addition to the differences in estimation strategies, our papers differ in focus. We look at consumers choices for new vehicles within the model year, while Schiraldi (2006) focuses on consumers choices across vintages.
} 
by retail firms. Work by Slade (1998), Aguirregabiria (1999), Pesendorfer (2002) and Hendel and Nevo (forthcoming), for example, use grocery retail data to show that temporal demand drive firm's pricing strategies-explaining, for example, the timing of temporary sales. Because these papers focus on products which are frequently purchased, the specific consumer behavior driving these pricing strategies differ from those examined in our paper.

This paper is also contributes to the literature focused on understanding various aspects of automobile pricing. A series of papers, Busse, Silva-Risso, and Zettelmeyer (2006), Zettelmeyer, Morton, and Silva-Risso (2003), and Busse, Simester, and Zettelmeyer (2007) analyze the impact of incentives, dealer inventories, and price cues, respectively, on consumer behavior. This paper adds to this line of research by quantifying consumer's temporal substitution and so providing a deeper understanding of whether automobile price discounts are drawing new customers into the market, or simply changing the timing of existing consumers' purchase decisions.

Finally, quantifying consumers' substitution patterns is also central to papers in the measurement literature, such as Aizcorbe, Bridgman, and Nalewaik (2007) and Aizcorbe and Copeland (2007), which focus on constructing true cost-of-living price indexes for infrequently purchased durable goods when consumers are heterogenous.

We structured the paper so that we first describe our data set (section 2). We then construct a structural model (section 3), layout our estimation strategy (section 4) and discuss how the parameters are identified (section 5). Finally, we present our results (section 6).

\section{Data}

The data we use covers the vast majority of the light motor vehicle market in the US. We use a dataset on monthly prices and sales by model and model year constructed in Copeland, Dunn, and Hall (2005). Unlike that paper, however, we include vehicles produced by foreign manufacturers because we are not concerned by the lack of information on overseas production. The sales data come from Wards Communications, while the price data are derived from retail transactions captured at dealerships by J.D. Power and Associates (JDPA). ${ }^{7}$ JDPA at-

\footnotetext{
${ }^{7}$ The price data were constructed by Corrado, Dunn, and Otoo (2006), who obtained it from J.D. Power and Associates.
} 
tempts to measure precisely the price customers pay for their vehicle, even adjusting the price when a dealership under or overvalues a customer's trade-in vehicle as part of a new vehicle sale. JDPA also reports the incentives customers received from the manufacturer by providing monthly information on the average cash rebate and average financial package received on each model and model year. ${ }^{8}$

Our data covers 48 months, from January 1999 to December 2003, and includes 302 models. Automobile manufacturers typically release new vintages for each model around August of each year, hence the dataset include 1999 through 2004 model-years. In addition to the price and sales data, we merged vehicle characteristic data (e.g. horsepower, weight and length) from Automobile News' Market Data Book (various years), which provide us with a rich set of observable characteristics for each vehicle.

As mentioned in the introduction, a striking feature of the automobile market is the constant decline in prices throughout the model year. Figure 1 illustrates the decline in prices by model year with a Laspeyres price index. This price decline is mainly driven by lower prices at the dealership-only one-third this fall is accounted for by financing incentives such as cash rebates and low interest loans.

As mentioned in the introduction, there are several possibilities besides temporal substitution that could explain automakers' pricing strategies. For example, Pashigian, Bowen, and Gould (1995) postulate that automobiles have a fashion component which falls in value the longer a car has been on the market. The fall in vehicle price over the model year may then simply reflect the decline in the fashion component of the vehicle.

Alternatively, the price decline could be a function of imperfect secondary markets. Used cars are typically priced based on their model year, not their date of production. Hence auto-

\footnotetext{
${ }^{8}$ To compute the value of financial package the consumer received, we use information from JDPA on the amount financed, interest rate, and loan term that the average customer received. The financial data are captured for loans that customers obtained from any financial institution, as long as the financing was arranged through the dealership. As a strong majority of car loans arranged through dealerships are made by the financing arms of manufacturers, we treat the financial data as an approximation of the average financial package that consumers received from manufacturers. To measure the value of these financial incentives to consumers, we compare the financial package in the data against a benchmark package offered by commercial banks. We make this comparison by first computing the net present value (NPV) of the average amount financed given the interest rate and loan term in the data. We then compute the NPV of financing the same average amount at the average interest rate reported for 48-month new car loans at commercial banks. The value of the manufacturer's financial incentive is then defined as the difference between the two NPV amounts.
} 


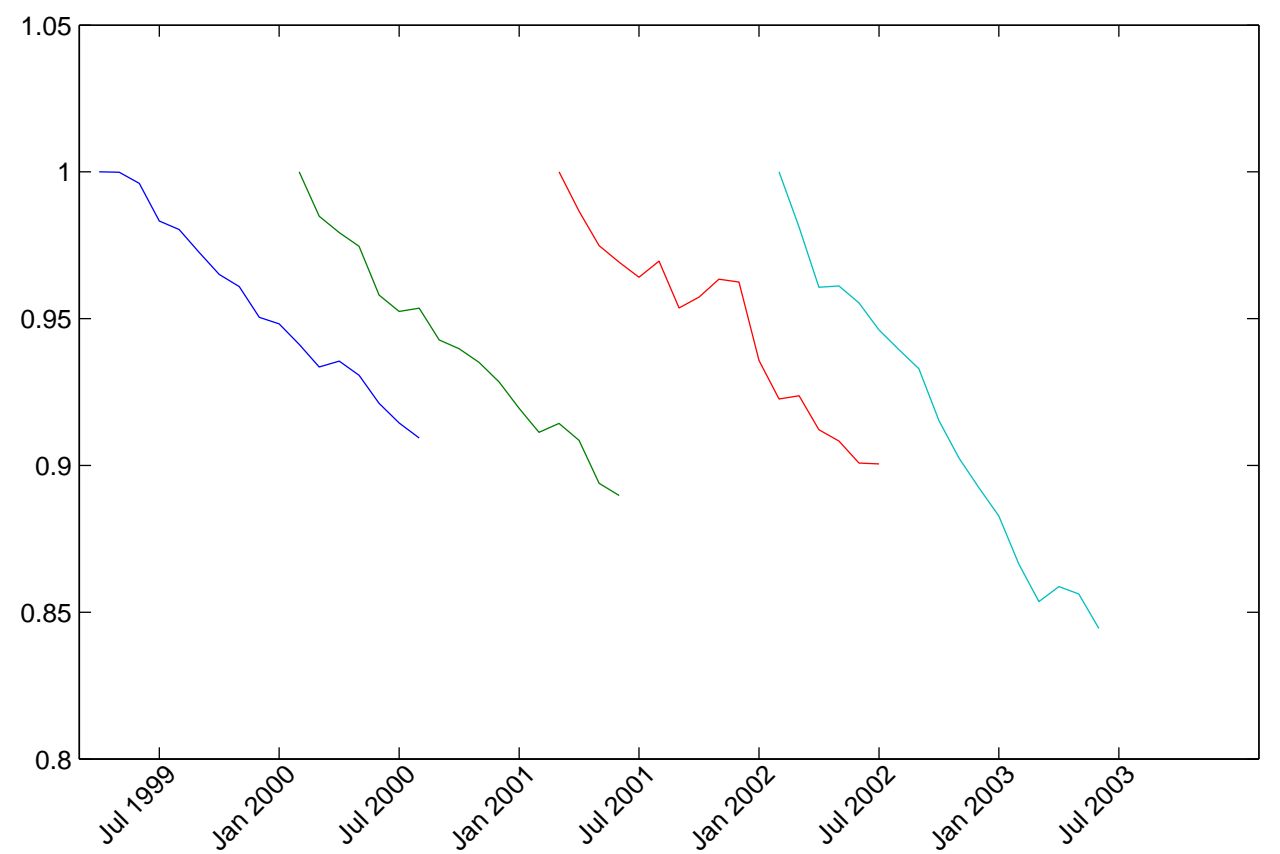

Figure 1: Laspeyres Price Indexes by Model Year 


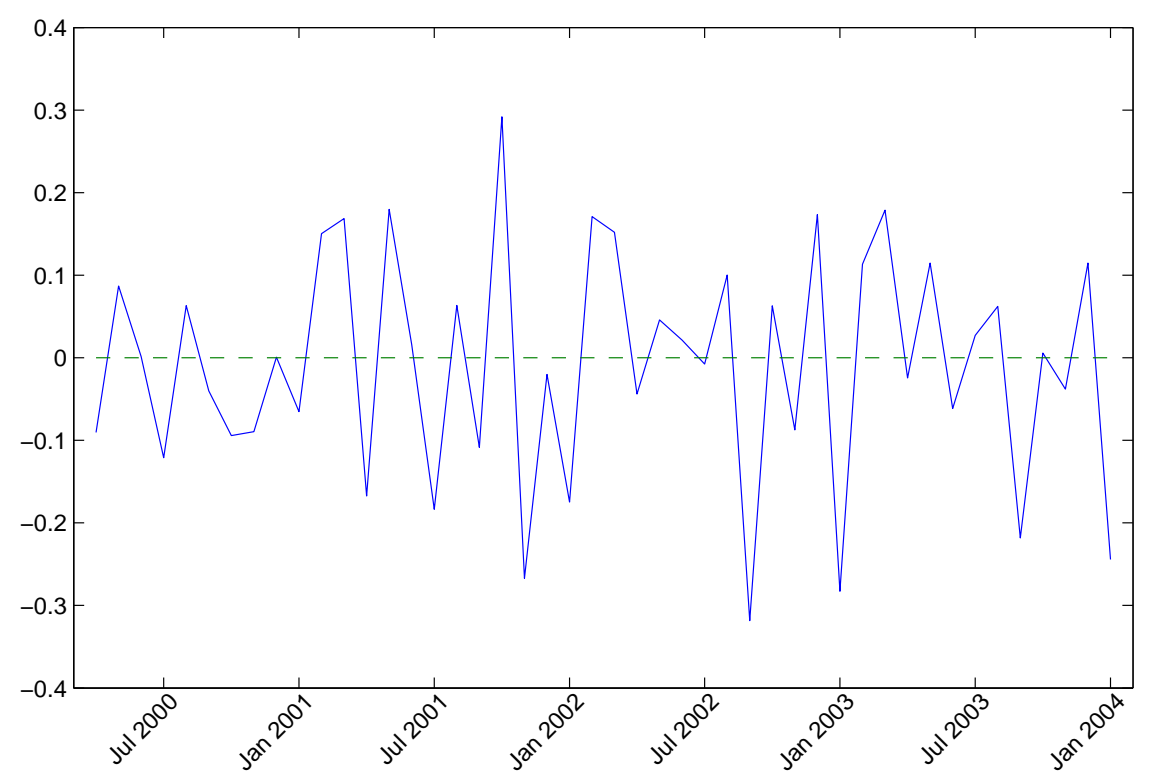

Figure 2: Percentage Change in Aggregate Sales

mobiles manufactured at the beginning and end of the model year have the same price on the used car market, not taking into account the second order price adjustments due to mileage. Industry wisdom is that customers take this imperfection in the used car market into account when purchasing a new vehicle, and so demand lower prices at the end of the model year. Hence, the price decline over the model year may represent the foregone value of driving services, rather than temporal price discrimination among heterogeneous consumers.

In this paper, we allow both temporal price discrimination as well as an exogenous decline in vehicle value over the product cycle in trying to explain the decline in vehicle prices. Because our model seeks to match both the time series of price and sales, we will be able to determine which is the significant force drives the motor vehicle market.

As noted in the introduction, total light vehicle sales are quite volatile. The percent change in aggregate sales follows a jagged pattern, with most positive percent changes followed by negative percent changes (see figure 2). A possible cause behind this volatility is the timing of purchases to take advantage of sales. We first explore the temporal relationship between sales and price through reduced form analysis.

To test for temporal substitution while controlling for the downward trend in prices, we use 


\begin{tabular}{ccccc} 
Mean & Std Dev & Median & Min & Max \\
\hline 0.0179 & 0.0178 & 0.0130 & 0 & 0.2443
\end{tabular}

Table 1: Statistics on the Absolute Value of the Price Residuals

a two stage least squares approach. We first de-trend both price and sales data by separately regressing the log of these two variables on a product cycle index and dummy variables for the calendar month and the model year, for each model in the sample. ${ }^{9}$ We then use these residuals, the deviations of price and sales from its trend, to test for consumer dynamics.

Before reporting the reduced form results, however, we analyze how much price moves around its trend. The mean and median of the absolute value of the price residuals is 0.018 and 0.013 respectively (see table 1). Hence, deviations from trend typically average 1 to 2 percent of the price level and the large standard deviations show there is a large amount of variation in these price residuals. This suggests that even if there is a secular decline in the value of vehicles over the model year, the substantial price variation around this trend still provides opportunities for consumers to "time" their purchases.

To test for the presence of temporal substitution while controlling for any trends in price and sales, we run the following regression, where $\left(\hat{s}_{t}, \hat{p}_{t}\right)$ denote the period $t$ sales and price residual respectively,

$$
\hat{s}_{t}=\beta_{0} \hat{s}_{t-1}+\beta_{1} \hat{p}_{t}+\beta_{2} \hat{p}_{t-1}+\varepsilon_{t} .
$$

This regression looks at the correlation of current period's deviation in sales with last period's deviation on price, controlling for the current price deviation and the sales deviation from last period. In a dynamic setting where rational agents are timing their durable goods decisions, we would expect temporary price discounts to have a strong effect on sales, or that $\beta_{2}>0$. Indeed, $\beta_{2}$ is estimated to be positive and significant (see the last row in table 2), suggesting that consumers delay their purchases when prices are above trend. These results are robust to adding a squared lagged sales residual term (whose sign is preserved) to the regression. In addition, including the price residual from the future period, $\hat{p}_{t+1}$, further reinforces the role of temporal substitution; the coefficient on $\hat{p}_{t+1}$ is positive and significant while the coefficient on

\footnotetext{
${ }^{9}$ We excluded from this analysis the few models in our sample with only one model year of data.
} 


\begin{tabular}{cccc}
\hline variable & coefficient & estimate & std error \\
$\hat{s}_{t-1}$ & $\beta_{0}$ & 0.482 & 0.008 \\
$\hat{p}_{t}$ & $\beta_{1}$ & -0.631 & 0.134 \\
$\hat{p}_{t-1}$ & $\beta_{2}$ & 0.500 & 0.134 \\
\hline
\end{tabular}

Table 2: Coefficient Estimates from Sales Residual Regression

$\hat{p}_{t-1}$ remains essentially unchanged and retains its statistical significance. Assuming perfect foresight, the positive coefficient on $\hat{p}_{t+1}$ suggests that consumers buy now, in anticipation of prices rising above trend next period.

To better measure the degree of temporal substitution that occurs in the light motor vehicle market, we develop and estimate a dynamic model of consumer behavior.

\section{Model}

To ensure the robustness of our empirical results and to better understand the limitations of our estimation strategy, we estimate the model consumer behavior in two ways. First, we consider a static model of consumer demand which we estimate using a well-understood empirical discrete-choice algorithm, similar to BLP and Petrin (2002). Second, we construct a dynamic model of consumer demand within the model-year. To estimate this more complicated model, we rely upon the discret-choice estimation technique laid out in Gowrisankaran and Rysman (2006).

\subsection{Static Model}

Under this first approach, consumer purchasing behavior is modeled within a static discretechoice framework. We construct the demand system by aggregating over the discrete choices of heterogeneous individuals.

We assume that consumers can only purchase one vehicle, and so consumers use the remainder of their income to purchase an alternative composite good. The indirect utility derived from choosing an automobile depends on the interaction between a consumer's characteristics and a product's characteristics. Consumers are heterogeneous in income as well as in 
their tastes for certain product characteristics. We distinguish between two types of product characteristics: those that are observed by the econometrician (such as size and height), which are denoted by $X$; and those that are unobserved by the econometrician (such as special automobile-service contracts), which are denoted by $\xi$. We model the effect of price on consumer's indirect utility through a distaste for price term, $\eta_{i}$. Following Berry, Levinsohn, and Pakes (1999) we assume that $\eta_{i}=\frac{\eta}{y_{i}}$ where $\eta$ is a parameter to be estimated and $y_{i}$ is a draw from the income distribution.

Let $J$ denote the set of vehicle models for sale and $T$ the number of months within the model-year. To apply this static framework to the consumer's inherently dynamic problem, we assume that months of the model year are simply another characteristic of a vehicle. Consequently, the set of choices a consumer faces with a model year is given by $J_{S} \equiv J \times T$. Dropping the subscript for years, we specify the indirect utility derived from consumer $i$ purchasing product $j \in J_{S}$, as

$$
u_{i j}=X_{j} \gamma+\xi_{j t}+\zeta C_{j}-\frac{\eta}{y_{i}} p_{j}+\sum_{k=1}^{K} \sigma_{k} v_{i k} x_{j k}+\varepsilon_{i j}
$$

where $p_{j}$ denotes the vehicle price and $x_{j k} \in X_{j}$ is the $k$ th observable characteristic of product j. $C_{j}$, an index from 1 to 12 , denotes which month in the model year a vehicle is sold. The parameter $\zeta$ then indirectly measures the cost of waiting to purchase a vehicle later in the model year. We denote the mean utility of a vehicle by $\delta_{j}$, and set it equal to $X_{j} \gamma+\xi_{j}+C_{j}$, where $\gamma$ are parameters to be estimated. Consumers then have a distribution of tastes over the observable characteristics. For each characteristic $k$, consumer $i$ has a taste $v_{i k}$, which is drawn from an independently and identically distributed (i.i.d.) standard normal distribution. The parameter $\sigma_{k}$ captures the variance in consumer tastes. Finally, $\varepsilon_{i j}$ is an i.i.d. extreme value.

\subsection{Dynamic Model}

Our second approach to modeling consumer behavior builds upon the static mode above, but we explicitly incorporate the cost to a consumer to waiting a month to purchase a vehicle. Using the same notation laid out above, we model consumers as solving a finite period optimal stopping problem. Each year, consumers enters the new model year with an income draw and choose if they want to buy a new vehicle and if so, when in the model year to purchase it.

As with the static model, we assume that consumers can only purchase one vehicle, and 
so consumers use the remainder of their income to purchase an alternative composite good. To separate the consumption of the alternative composite good from the timing of the motor vehicle purchase, we assume consumers can use capital markets to perfectly smooth their consumption of the alternative composite good over the model year. We model the perfect smoothing assumption by discounting the distaste for price term as if it occurs in the last month of the model year. Hence, the consumer $i$ 's indirect utility from purchasing a vehicle $j \in J$ in month $t \in T$ of a model year is given by

$$
u_{i j t}=X_{j t} \gamma+\xi_{j t}+\zeta C_{t}+\sum_{k=1}^{K} \sigma_{k} v_{i k} x_{j k}+\varepsilon_{i j t}-\beta^{T-t} \frac{\eta}{y_{i}} p_{j t}
$$

where $\beta$ is the monthly discount factor. Letting $\pi_{i t}$ denote the utility flow from using an outside option, such as a used car or public transportation, the consumer's problem in the last period of the model year is

$$
V_{T i}=\max \left\{\pi_{i T}, \max _{j \in J}\left\{u_{i j T}\right\}\right\}
$$

In this final period of the stopping problem, the consumer weighs the value of purchasing a new car against continuing to use their alternative transportation option and spending all their money an outside good. For $t=1,2, \ldots T-1$, the consumer's problem is

$$
V_{t i}=\max \left\{\pi_{i t}+\beta V_{t+1, i}, \max _{j \in J}\left\{u_{i j t}\right\}\right\}
$$

The problem becomes dynamic because the consumer weighs purchasing and enjoying a new vehicle now, versus waiting at least one period before purchasing. As such, the consumer's option value, $V_{t+1, i}$ plays a decisive role in the consumer's decision.

Currently, we assume that consumers have perfect foresight over the availability of vehicles, vehicle characteristics, and prices within the model year. Given that the vehicle choice set and vehicle characteristics do not change over the model year, perfect foresight is an entirely reasonable assumption in this regard. Being able to perfectly forecast prices over the model year, however, is a stronger assumption. Relaxing this assumption imposes large computational costs, especially given the more than 200 vehicles available for purchase. Further, 
for the purposes of this paper, the gain to incorporating uncertainty over future prices seems small. Indeed, due in part to heavy advertising, consumers seem well aware of the decline in car prices over the model year. Hence perfect foresight does not seem to be a restrictive assumption. Finally, perfect foresight allows for an easier comparison between the static and dynamic models presented above.

\section{Estimation strategy}

In this section we detail the estimation strategies for the static and dynamic models described above.

\subsection{Static Model}

Our estimation strategy follows the generalized method of moments approach taken by BLP. Given the vector of non-linear parameters $(\eta, \sigma)$, we solve for the unique vector of mean utilities such that the model's predicted market shares equal actual market shares. We then match the moments related to the market-level disturbance, $\xi_{j}$, using the assumption that $\xi$ is uncorrelated with the vehicle characteristics, $X$, or

$$
E[\xi(\eta, \sigma) \mid X]=0
$$

Using a least-squares approach, we then decompose the estimated mean utility of each vehicle into two parts,

$$
\delta_{j}=X_{j} \beta+\xi_{j}+\zeta C_{j}
$$

An endogeneity problem arises as $\xi$ may be correlated with price. Berry (1994) provides a methodology that allows us to use instrumental variables. The usual instruments used in this setting are product characteristics, however these have little power in our setting as they are constant over the model year. So in addition to product characteristics, our instruments also include dealership inventory levels of competing cars at a monthly frequency. ${ }^{10}$ We use the sum of inventories of competing vehicles within the same market segment, of competing man-

\footnotetext{
${ }^{10} \mathrm{We}$ obtained model-level inventory data from Wards Communications
} 
ufacturers, and of all other vehicles on the market. While own-vehicle inventories will likely be correlated with $\xi$, inventories of competing vehicles should have little to no correlation with a vehicle's unobserved characteristic. Because inventories are a function of market segment demand shocks, these instruments are correlated with a vehicle's price.

Similar to Petrin (2002), we augment the moments specified above with a second set of moments. Using results from Aizcorbe, Bridgman, and Nalewaik (2007) we construct moments around the mean income of new light vehicle purchasers in each quarter of the automotive model year.

To define the total market for new vehicles and the share of the outside good, we follow the literature in assuming that all households are looking for a new vehicle. The total number of households is taken from the Current Population Survey's Annual Social and Economic Supplement for years 2000 to 2004. For the years we consider, there are a little over 100 million households and a little over 16 million new light vehicle sales. From this same survey, we also use the distribution of household income.

\subsection{Dynamic Model}

The estimation algorithm for the dynamic model is more complicated version of that presented above. As before, we use a GMM algorithm with the same two sets of moments described in the previous section. In the dynamic setting, however, solving for the mean utilities of vehicles whereby the model's predicted market shares exactly match the data is more complicated. Following the approach proposed by Gowrisankaran and Rysman (2006), we mixes techniques from the discrete-choice literature with an optimal stopping model. ${ }^{11}$ For every choice of the non-linear parameters, $(\eta, \sigma)$, we start with an initial guess of $\left\{V_{t i}\right\}$, the option values of consumers. Following the technique detailed in Berry (1994), we then back out the mean utilities $\delta_{j t}$ for each vehicle in each month of the model year. Using this new vector of mean utilities, we then compute a new set of value functions through backwards induction. We then use these new value functions to compute a new vector of mean utilities. These iterations continue until the difference between the iterations for both the vector of mean values and

\footnotetext{
${ }^{11}$ Gautam Gowrisankaran generously sent me the program he used to estimated the dynamic demand model in Gowrisankaran and Rysman (2006). I used his program as a guide to write the code used to estimate the model presented in the current paper.
} 
the value functions becomes sufficiently small. Given a final vector of mean utilities that is consistent with a vector of value functions, we can then use ordinary least squares to estimate $\{\gamma, \zeta\}$ and back out the vector of unobservable characteristics, $\xi$, for vehicles in each period and evaluate our first set of moments. Finally, we compute the second set of moments-the mean income of consumers that purchase a vehicle for every quarter of the model year and compute the GMM loss function.

As in the static model, we assume all households in the population are in the market for a new vehicle. So in the first month of the model year, all households consider purchasing a new vehicle. To be consistent with the optimal stopping model, however, in the second month, we assume that only those households that did not purchase a new vehicle in the first month are potential consumers, and so on. We model this shrinking of the number of customers by assuming each consumer $i$ is representative of a type of household that has mass 1 . After the first month of the model-year, this mass of consumers shrinks by the probability of consumer $i$ buying any new vehicle (i.e. buying an inside good). This same algorithm is applied after each month in the model year, to properly account for the different purchasing patterns of consumer types. We use the same data sources as in the static model to describe the total market for new vehicles and the income of potential purchasers.

The same endogeneity problem that exists in the estimation of the static model also applies here. We use the same set of instruments described in the previous section to account for this endogeneity.

\subsection{Data Preparation}

In taking the different versions of the optimal stopping models to the data, we had to slightly pare the data. The model is designed to consider consumers' purchase decisions within the model year, not across model years. In the U.S., there is a overlap period in the fall and early winter where the latest two vintages of vehicles are simultaneously sold on the new car market. We assume that consumers, when shopping for a new vehicle, only consider the newest vintage available. The older vintage is relegated to the outside option. We make this assumption to simplify the consumer's problem, and focus on how consumers' evaluate future price changes, keeping the choice set constant. Incorporating expectations over changes in the choice set vastly complicates the consumers' problem, with little economic value. As detailed in table 3, 


\begin{tabular}{c|cccccc}
\hline Model year & \multicolumn{2}{|c}{ All Data } & \multicolumn{2}{c}{ Pared Data } & \multicolumn{2}{c}{ Difference } \\
& $\begin{array}{c}\text { Unit Sales } \\
\text { (thousands) }\end{array}$ & $\begin{array}{c}\text { Revenue } \\
\text { (millions) }\end{array}$ & $\begin{array}{c}\text { Unit Sales } \\
\text { (thousands) }\end{array}$ & $\begin{array}{c}\text { Revenue } \\
\text { (millions) }\end{array}$ & $\begin{array}{c}\text { Unit Sales } \\
(\%)\end{array}$ & $\begin{array}{c}\text { Revenue } \\
(\%)\end{array}$ \\
\hline 2000 & 17,400 & 409,000 & 14,900 & 353,000 & 6.7 & 6.4 \\
2001 & 16,200 & 384,000 & 13,800 & 326,000 & 7.0 & 7.1 \\
2002 & 17,100 & 403,000 & 14,700 & 349,000 & 6.6 & 6.2 \\
2003 & 16,500 & 380,000 & 13,800 & 321,000 & 7.8 & 7.3 \\
Total & 67,200 & $1,576,000$ & 57,200 & $1,349,000$ & 7.0 & 6.8 \\
\hline
\end{tabular}

Table 3: The Effect of Paring the Data

limiting the model year to 12 months only eliminated 7 percent of sales and 7 percent of revenue. We constructed the 12 month model year by assuming it started in August of every year. Sales of a particular vintage that occurred before or after this 12 month period were discarded, though the vast majority of the discarded data came from sales after 12 months. Supporting our modeling assumption, Copeland, Dunn, and Hall (2006) find that within the new light motor vehicle market, cross-price elasticities across vintages of the same model are quite small relative to the cross-price elasticities across the same vintage of different models within the same market segment.

In addition to considering only the first 12 months of each model year, we drop the 1999 and 2004 model years because we do not observe significant portions of those product cycles. As such, our data consists of the 2000 to 2003 model years. These four model years include 266 models and consist of 9,485 observations.

\section{Identification}

The parameters in both the dynamic and static models are identified in a similar manner as in BLP and Gowrisankaran and Rysman (2006). Intuitively, within the model year we observe consumers' purchase decisions over the same choice set when facing different price vectors. ${ }^{12}$ This variation identifies the consumers' valuation of product characteristics and any

\footnotetext{
${ }^{12}$ Because we observe large price changes over time for a given choice set, we avoid the criticism of Ackerberg and Rysman (2005). They show that discrete choice models which primarily rely on changes in the choice set to estimate price elasticities will likely produce biased results.
} 
heterogeneity in consumers' preferences. In addition, the set of income moments describing the average income of new vehicle purchasers plays a large role in identifying the parameter valuing the alternative composite good, $\eta$.

Recall that our utility specification has a model-year trend component, to capture exogenous, systematic decreases in utility over the model year. As discussed earlier, this trend could be due to a decrease in a vehicle's fashion component, or reflect imperfections in the secondary market. Even with this trend component, however, $\eta$ and other utility parameters are identified by the substantial variation in prices around trend (see the reduced form results in section 2) and the set of income moments. A last source of identification comes from the same set of consumers showing up across model years and so facing different choice sets.

For the dynamic model, we do not attempt to estimate the consumer's discount rate, $\beta$. As detailed in Engle and McFadden (1994) and Magnac and Thesmar (2002), the discount rate is rarely identified in these settings. In our environment the timing of consumer decisions could be a function of impatience or the relative utility value of motor vehicle services versus the alternative composite good. Accordingly, we set consumers' monthly discount rate to 0.9957 .

\section{Results}

In this section we present the model parameter estimates from both the static and dynamic models. To illustrate the importance of temporal substitution, we then present the results from a series of counterfactual exercises.

\subsection{Parameter estimates}

In the empirical specification we choose to include 4 vehicle characteristics along with a constant term and a measure of variety in the linear specification of utility. These characteristics are a measure of acceleration (horsepower over weight), miles per dollar (miles per gallon divided by the price of gas per gallon), height, and size (length times width). ${ }^{13}$

The measure of variety is the number of vehicles in inventory (i.e. on dealer's lots) divided by the average inventory level for the corresponding market segment. Increased inventories

\footnotetext{
${ }^{13}$ We normalized each characteristic by dividing through by its maximum value.
} 


\begin{tabular}{ll|cccc}
\hline & Parameter & \multicolumn{2}{|c}{ Static Model } & \multicolumn{2}{c}{ Dynamic Model } \\
\hline \hline Mean & Constant & -16.408 & $(0.555)$ & -32.879 & $(1.184)$ \\
& Acceleration & 0.002 & $(0.001)$ & 2.582 & $(2.556)$ \\
& Miles per dollar & -30.085 & $(1.778)$ & 12.560 & $(0.696)$ \\
& Height & -0.057 & $(0.010)$ & 5.359 & $(0.383)$ \\
Variance & Size & $-2 \mathrm{e}-5$ & $(4 \mathrm{e}-5)$ & 9.058 & $(2.601)$ \\
& Constant & 19.142 & $(1.921)$ & 12.218 & $(2.485)$ \\
& Acceleration & 4.663 & $(1.101)$ & 6.989 & $(1.032)$ \\
& Size & 5.515 & $(2.372)$ & 4.635 & $(4.206)$ \\
Variety & US brand & 7.516 & $(0.373)$ & 4.296 & $(1.039)$ \\
Model-year trend & $\zeta$ & 0.164 & $(0.020)$ & 4.490 & $(0.545)$ \\
\hline Income & $\eta$ & -0.045 & $(0.012)$ & 1.202 & $(0.143)$ \\
\hline \hline
\end{tabular}

note: Standard errors are in parenthesis.

Table 4: Parameter Estimates

provides consumers with a greater variety of options for vehicles. Within a matching framework, this increased variety leads to better matches between consumers and their ideal vehicle, leading to higher utility. ${ }^{14}$ We do not simply use the level of inventories as our measure of variety, because the number of dealerships by market segment varies. Intuitively, vehicles that appeal to buyers across the U.S. will require larger amounts of inventory to achieve the same level of variety, relative to less popular vehicles only sold in parts of the country. MercedesBenz, for example, only had 191 dealerships in the U.S. in 2002, while Honda had 959. ${ }^{15}$ Dividing through by the mean allows us to compare the inventory accumulation, and its resulting effect on variety, of popular vehicles such as pickups to other vehicles.

For the non-linear portion of utility, $\sum_{k=1}^{K} \sigma_{k} v_{i k} x_{j k}$ in equation 3, we include acceleration, height, size, a constant term and a US brand loyalty terms. The US brand term is an indicator function equal to one if the manufacturer of a vehicle is Chrysler, Ford or General Motors.

The parameter estimates from both models are presented in table 4. Most of the param-

\footnotetext{
${ }^{14}$ This measure of variety is the same used in Copeland, Dunn, and Hall (2006). They explicitly incorporate a measure of variety within their static model of demand estimation for motor vehicles, and find that variety plays a significant role within this industry.

${ }^{15}$ Data taken from Ward's 2002 Automotive Yearbook.
} 
eter estimates are precisely estimated. ${ }^{16}$ Turning first to the static model, the mean value of the constant term is negative, implying that households on average place a negative value on purchasing a new car. This result is driven by the fact that less than 15 percent of households purchase a new vehicle over the model year. Given that the option of not buying a car has been normalized to zero, the vast majority of households' utility gain from purchasing a new vehicle must be negative. Further ensuring that the vast majority of households do not purchase a new vehicle, the model assigns a large negative value to miles per dollar.

In accordance with past results in the literature, the static model predicts there is substantial heterogeneity across consumers. The model finds there is significant variation in the taste for acceleration and size. The large variance on the constant term implies varying tastes in the value of purchasing any new motor vehicle, helping the model to match the fact that most households are not purchasing a new vehicle.

Over the model year, the variety term increases in a non-linear fashion as dealerships stockpile vehicles. Reinforcing the results of Copeland, Dunn, and Hall (2006), our estimate of a positive coefficient on variety implies that increases inventory have a positive effect on demand. Inline with the fashion hypothesis advanced by Pashigian, Bowen, and Gould (1995), the coefficient on the model-year trend is negative.

Finally, the income parameter $\eta$ measures consumers sensitivity to price, where larger values of $\eta$ imply an increased distaste for price. The parameter is precisely estimated and, as demonstrated in the counterfactuals presented below, implies that consumers are quite sensitive to changes in price.

Reassuringly, the parameter estimates from the dynamic model are not much different from their counterparts in the static model. The mean value to purchasing a car is negative and large in absolute value. Further, there is a lot of consumer heterogeneity around the utility from purchasing a new vehicle, as well as in consumers tastes for vehicle characteristics. The largest difference occur with consumers' valuation of variety and the coefficient on the model-year trend. This differences cast doubt on the variety and model-year trend coefficients estimated by the static model, and reinforce the important of properly accounting for the dynamics of the consumer's problem.

Both models are able to closely match the moments describing the average income of new

\footnotetext{
${ }^{16}$ The standard errors do not allow for autocorrelation in the unobserved term, though this is something for which we will correct in future versions of this paper.
} 


\begin{tabular}{cccc}
\hline & \multicolumn{3}{c}{$\begin{array}{c}\text { Income } \\
\text { (thousands of dollars) }\end{array}$} \\
\hline Quarter & Data & Static Model & Dynamic Model \\
1 & 74.973 & 75.539 & 72.994 \\
2 & 73.075 & 73.030 & 71.475 \\
3 & 71.460 & 70.229 & 69.375 \\
4 & 68.603 & 69.272 & 69.531 \\
\hline
\end{tabular}

Table 5: Average Income of New Vehicle Purchasers

vehicle purchasers over the model year well. Table 5 lists the moments taken from Aizcorbe, Bridgman, and Nalewaik (2007) and the outcomes produced by the static and dynamic models.

\subsection{Price elasticities}

From the estimated parameters it is not obvious what the magnitude of consumers' own and cross price elasticities. To gauge how willing consumers are to substitute both cross within the same month and across months, we compute the own and cross-price elasticities for all vehicles. Below are the results from the static model. Results from the dynamic model are to come.

Table 6 presents, at the market segment level, statistics on the own and cross-price elasticities for the static model for the 2002 model year. The cross-price elasticity statistics are computed using only those vehicles within the same market segment, so as to ignore the especially small cross-price elasticities between unlike vehicles. The estimates of median own-price elasticities by market segment are in the neighborhood of 3, consistent with other empirical work on the automobile industry, such as BLP. One concern with these estimates, however, is the lack of meaningful variation in these own-price elasticities across market segments. Past work has shown larger own-price elasticities for compact cars relative to upscale cars, a pattern not seen in our estimates from the static model.

The cross-price elasticities are puzzling because of their insignificant size. Vehicles within the same market segment should be good substitutes for another, yet the estimated cross-price elasticities are tiny. 


\begin{tabular}{|c|ccc|ccc|}
\hline $\begin{array}{c}\text { Market } \\
\text { Segment }\end{array}$ & \multicolumn{2}{|c|}{ Own-Price Elasticities } & \multicolumn{3}{c|}{$\begin{array}{c}\text { Cross-Price Elasticities } \\
\text { (within market segment) }\end{array}$} \\
& Min & Median & Max & Min & Median & Max \\
\hline Midsize & -4.82 & -3.42 & -1.91 & $4 \mathrm{e}-7$ & 0.0018 & 0.0213 \\
Pickup & -4.75 & -3.80 & -2.76 & $3 \mathrm{e}-5$ & 0.0047 & 0.0269 \\
SUV & -4.83 & -3.11 & -2.15 & $6 \mathrm{e}-8$ & 0.0010 & 0.0346 \\
Compact & -4.37 & -3.23 & -1.49 & $6 \mathrm{e}-7$ & 0.0019 & 0.0206 \\
Sporty & -7.04 & -2.91 & -1.56 & $3 \mathrm{e}-8$ & 0.0004 & 0.0115 \\
Traditional & -5.14 & -3.85 & -2.80 & $4 \mathrm{e}-5$ & 0.0014 & 0.0066 \\
Upscale & -5.90 & -3.18 & -2.07 & $5 \mathrm{e}-8$ & 0.0006 & 0.0162 \\
Vans & -5.73 & -3.97 & -2.59 & $4 \mathrm{e}-6$ & 0.0017 & 0.0170 \\
\hline
\end{tabular}

Table 6: Static Model-Price Elasticities for the 2002 Model Year

Unlike in the static model, the own and cross-price elasticities implied by the dynamic model must be computed numerically. (WORK STILL NEEDS TO BE DONE).

\subsection{Dynamic Model Counterfactuals}

Complementing the analysis of the own and cross-price elasticities, we use the dynamic model to consider a series of counterfactuals where prices are temporarily discounted for a month. These exercises provide a different look at consumers' overall willingness to substitute both within and across months. All discounts are 5 percent price reductions that occur in the 8th month of the 2002 model year (March 2002) and are anticipated by consumers. First, we examine consumer substitution patterns when Ford's Crown Victoria goes on sale. Second we consider the case when all of Ford's vehicles are discounted. Third, we run the counterfactual where all vehicles in the Crown Victoria's market segment, "Traditional" automobiles, are put on sale.

We begin by considering a temporary price reduction of Ford's Crown Victoria. Simulating the model, we get the puzzling result that there is tremendous cross-sectional substitution by consumers, but hardly any temporal substitution. As illustrated on table 7, the 5 percent sale on the Crown Victoria (a discount of more than $\$ 1,100$ ) caused two purchasers of Crown Victoria to delay their purchase decision. From the month 8 perspective, the 5 percent price decrease resulted in an increase in quantity sold of almost 12 percent. For the model year, 


\begin{tabular}{|c|cc|c|}
\hline $\begin{array}{c}\text { Product Cycle } \\
(2001)\end{array}$ & \multicolumn{2}{|c|}{ Crown Victoria Sales } & Difference \\
\hline 1 & 1,373 & 1,373 & 0 \\
2 & 2,474 & 2,474 & 0 \\
3 & 4,722 & 4,722 & 0 \\
4 & 5,708 & 5,708 & 0 \\
5 & 5,345 & 5,344 & 1 \\
6 & 7,197 & 7,197 & 0 \\
7 & 8,060 & 8,059 & 1 \\
8 & 5,937 & 6,645 & -708 \\
9 & 5,108 & 5,108 & 0 \\
10 & 4,108 & 4,108 & 0 \\
11 & 4,969 & 4,969 & 0 \\
12 & 3,590 & 3,590 & 0 \\
\hline Annual Model sales & 58,589 & 59,296 & -706 \\
\hline Total Market sales & $14,679,787$ & $14,680,192$ & -405 \\
\hline
\end{tabular}

Table 7: 2001 Crown Victoria Sale Counterfactual

\begin{tabular}{c|cc} 
& Units & Percent \\
\hline Increase in month 8 Crown Victoria sales & 708 & - \\
\hline From consumers of new vehicles & 303 & 43 \\
temporal & 2 & 0.7 \\
cross sectional & 301 & 99.3 \\
From consumers of the outside good & 405 & 57
\end{tabular}

Table 8: The Sales Substitution Pattern in response to the Crown Victoria Sale 
Crown Victoria sales are up 706 units, a 1.2 percent increase in annual sales. For the market as a whole, light vehicle sales are up 405 units, indicating a large share of new consumers entered the market in response to the sale.

These results indicate a substantial boost in new customers, given the 5 percent price discount. But the implied substitution patterns are troubling. Overall, only 2 consumers made temporal adjustments in response to the Crown Victoria sale (see table 8). These results lack credibility. It is difficult to reconcile consumers' lack of a temporal response to such a large price change, especially because consumers face the same choice set within a model year. Further, the large cross-sectional response demonstrates that consumers are price sensitive. The lack of temporal substitution is not particular to the Crown Victoria, but is a consistent response across vehicles.

The second counterfactual considers consumers' behavior when all of Ford's vehicles are placed on sale. As before, the price reduction is 5 percent and the sale is temporary, only applied in month 8 of the model year. In contrast to the previous counterfactual, this exercise generates enormous amounts of temporal substitution, which dominates the cross sectional substitution effects. Table 9 outlines the monthly total sales patterns in the data and under the counterfactual. In the counterfactual, 92 percent of the substitution is temporal (see table 10), with consumers from all months delaying or pushing up the timing of their purchases. Interestingly, the absolute number of cross-sectional switchers is of the same magnitude as the number of temporal switchers for any given month.

We reconcile the results from these two counterfactuals by noting that the model consistently predicts low amounts of cannibalization given temporary sales (i.e. of consumers continuing to buy the same vehicle, but switching to the month when it is on sale). In the first counterfactual, only 2 consumers switched the timing of their new Crown Victoria purchase. For the second counterfactual, Ford sells 34,129 more units overall; hence most consumers who switched were not previous consumers of Ford vehicles. This implies that from a consumer's point-of-view, vehicles in general are quite substitutable. Further, consumers are price sensitive. In both counter-factuals, substantial numbers of consumers switched their purchase decisions in response to the price discounts.

There is little temporal substitution in the first counter-factual, however, because the price discount on the Crown Victoria had almost no effect on consumers' option value, $V_{t i}$. This 


\begin{tabular}{|c|cc|c|}
\hline \multirow{2}{*}{$\begin{array}{c}\text { Product Cycle } \\
(2001)\end{array}$} & \multicolumn{2}{|c|}{ All Vehicle Sales } & Difference \\
\hline 1 & 496,027 & 495,473 & 554 \\
2 & $1,121,653$ & $1,120,393$ & 1,260 \\
3 & $1,092,389$ & $1,091,153$ & 1,236 \\
4 & $1,174,588$ & $1,173,249$ & 1,339 \\
5 & $1,035,168$ & $1,033,981$ & 1,187 \\
6 & $1,238,045$ & $1,236,616$ & 1,429 \\
7 & $1,430,983$ & $1,429,319$ & 1,664 \\
8 & $1,367,780$ & $1,403,738$ & $-35,958$ \\
9 & $1,420,850$ & $1,419,323$ & 1,527 \\
10 & $1,433,464$ & $1,431,920$ & 1,544 \\
11 & $1,403,050$ & $1,401,533$ & 1,517 \\
12 & $1,465,791$ & $1,464,201$ & 1,590 \\
\hline Total Market sales & $14,679,787$ & $14,700,899$ & $-21,112$ \\
\hline
\end{tabular}

Table 9: 2001 Ford Sale Counterfactual

\begin{tabular}{c|cc} 
& Units & Percent \\
\hline Increase in month 8 sales & 37,215 & - \\
\hline From consumers of new vehicles & 16,103 & 43 \\
temporal & 14,846 & 92 \\
cross sectional & 1,257 & 8 \\
From consumers of the outside good & 21,112 & 57
\end{tabular}

Table 10: The Sales Substitution Pattern in response to Sale on all Ford Models 


\begin{tabular}{c|cc} 
& Units & Percent \\
\hline Increase in month 8 Traditional model sales & 4,377 & - \\
\hline From consumers of new vehicles & 1,893 & 43 \\
temporal & 1,711 & 90 \\
cross sectional & 182 & 10 \\
From consumers of the outside good & 2,484 & 57 \\
\hline
\end{tabular}

Table 11: The Sales Substitution Pattern in response to Sale on all Traditional Models

is due, we believe, to the logit error term embedded in consumers' indirect utility functions. Because of the large choice set, each period a consumer receives over 200 error draws, which drown out the temporal effects of small price discounts.

In contrast, the large price discount resulting from placing Ford's entire product line on sale overcomes the logit error noise and generates a significant change in a consumer's option values. Because discounting has a small effect in the consumer's problem, changes in consumers' option values have substantial effects across all months. This leads to a substantial temporal response that dominates the cross-sectional substitution.

To highlight the model's predictions that most vehicles are good substitutes for one another, we consider a third counterfactual where all vehicles within the "Traditional" market segment go on sale. ${ }^{17}$ As before, we simulate the model for a 5 percent price discount in the eight month of the 2002 model year. Similar to the second counterfactual, there is a large amount of temporal substitution in response to the price discounts, relative to a small amount of cross-sectional substitution (see table 11). Further the source of consumers who switched to purchasing a traditional vehicle is diverse. Consumers switched from all market segments, highlighting the model's result that there is a high level of substitutability across most vehicle models. Table 12 breakdowns, percentage-wise, from which market segment came those switching consumers. The market segments midsize, pickups, and SUV, roughly account for 20 percent each of the consumers who switched to purchasing a the discounted traditional vehicle. While these magnitudes demonstrate people's willingness to switch, it is important to keep in mind that these three market segments are also relative large segments.

\footnotetext{
${ }^{17}$ This small segment includes 7 vehicles: Avalon, Bonneville, Concorde, Crown Victoria, Grand Marquis, LHS, and Lesabre.
} 


\begin{tabular}{|c|c|c|}
\hline \multirow[b]{2}{*}{ Market Segment } & \multicolumn{2}{|c|}{ Source of Substitution } \\
\hline & $\begin{array}{c}\text { Temporal } \\
\text { (percent) }\end{array}$ & $\begin{array}{l}\text { Cross sectional } \\
\quad \text { (percent) }\end{array}$ \\
\hline Midsize & 27.5 & 28.8 \\
\hline Pickup & 18.1 & 18.8 \\
\hline SUV & 24.8 & 23.2 \\
\hline Small & 9.8 & 10.1 \\
\hline Sporty & 2.7 & 3.1 \\
\hline Traditional & 2.7 & - \\
\hline Upscale & 5.8 & 6.0 \\
\hline Vans & 8.6 & 10.0 \\
\hline
\end{tabular}

Table 12: Source Distribution of Switching Consumers

\section{Conclusion}

In this paper we estimate a dynamic demand model for light motor vehicles. We show that consumers are quite price sensitive, but that temporal substitution plays a minimal role in this market unless large enough price discounts are offered. When such an event occurs, however, there is substantial temporal substitution. We are surprised by these results and believe more work needs to be done to verify these results. Further, we believe that the more work should be exploring the role of logit error terms in these results. in particular, we plan on estimating a pure-characteristics version of this model (see Bajari and Benkard (2005)) and comparing its predictions to those presented here.

Incorporating dynamics into the demand system for motor vehicles is an important step to help answer a multitude of other questions. In another paper we aim to analyze the price index implied by our model and compare it to existing measures (which are derived from static models of demand). Other research agendas include expanding this dynamic model to include consumers' substitution patterns across different vintages and adding a supply side to the model. 


\section{References}

ACKERBERG, D., AND M. RYSMAn (2005): "Unobserved product Differentiation in discretechoice models: estimating price elasticities and welfare effects," RAND Journal of Economics, 36, 771-788.

Aguirregabiria, V. (1999): "The dynamics of markups and inventories in retailing firms," Review of Economic Studies, 66, 275-308.

Aizcorbe, A., B. Bridgman, And J. NALEwAik (2007): “The Implications of Heterogeneous Buyers for Measuring Quality Change,’ Bureau of Economic Analysis mimeo.

Aizcorbe, A., And A. Copeland (2007): "Intermittent Purchases and Welfare-Based Price Deflators for Durable Goods," BEA working paper WP2007-02.

BAJARI, P., AND L. BEnKARD (2005): "Demand Estimation With Heterogeneous Consumers and Unobserved Product Characteristics: A Hedonic Approach," Journal of Political Economy.

BERRY, S. (1994): "Estimating discrete choice models of product differentiation," RAND Journal of Economics, 71, 581-611.

Berry, S., J. Levinsohn, And A. PAKes (1995): “Automobile Prices in Market Equilibrium," Econometrica, 63, 841-890.

(1999): "Voluntary export restraints on automobiles: Evaluating a trade policy," American Economic Review, 89, 400-430.

Berry, S., AND A. PAKes (forthcoming): "The Pure Characteristics Model of Demand," International Economic Review.

Busse, M., J. Silva-Risso, and F. Zettelmeyer (2006): "\$1000 Cash Back: The PassThrough of Auto Manufacturer Promotions," American Economic Review, 96, 1253-70.

Busse, M., D. Simester, and F. Zettelmeyer (2007): “The Best Price You'll Ever Get: The 2005 Employee Discount Pricing Promotions In the US Automobile Industry," NBER Working Paper 13140. 
CARranZA, J. E. (2003): "Product innovation decisions in durable goods markets," Unpublished dissertation.

— (2006): "Estimation of demand for differentiated durable goods," manuscript.

Conlisk, J., E. Gerstner, And J. Sobel (1984): “Cyclic Pricing by a Durable Goods Monopolist," The Quarterly Journal of Economics, 99, 489-505.

Copeland, A., W. Dunn, And G. Hall (2006): "Prices, Production and Inventories Over the Automobile Model Year," NBER Working Paper 11257.

Corrado, C., W. Dunn, And M. OTOo (2006): "Incentives and Prices for Motor Vehicles: What Has Been Happening in Recent Years?, FEDS working paper 2006-9.

Engle, R., And D. MCFAdDEN (eds.) (1994): Handbook of Econometricschap. 51, pp. 3081-3143. North Holland, 4 edn.

Gordon, B. (2006): "Estimating a dynamic model of demand with durable goods," mimeo.

Gowrisankaran, G., And M. Rysman (2006): "Determinants of Price Declines for New Durable Goods," mimeo.

Hall, G. (2000): "Non-Convex Costs and Capital Utilization: A Study of Production Scheduling at Automobile Assembly Plants," Journal of Monetary Economics, 45, 681716.

HENDEL, I., AND A. NEvo (forthcoming): “Sales and Consumer Inventory,” RAND.

LAZEAR, E. P. (1986): “Retail Pricing and Clearance Sales," American Economic Review, 76, $14-32$.

Magnac, T., And D. Thesmar (2002): "Identifying dynamic discrete decision processes," Econometrica, 70, 801-816.

Melnikov, O. (2000): "Demand for Differentiated Durable Products: The Case of the U.S. Computer Printer Market," Yale University Mimeo. 
NAIR, H. (2005): "Dynamics of pricing in durable goods markets: Applications to 32-bit console video games," manuscript.

Pashigian, P., B. Bowen, And E. Gould (1995): "Fashion, styling, and the within season decline in automobile prices," Journal of Law and Economics, 38, 281-310.

PAShigian, P. B. (1988): "Demand Uncertainty and Sales: A study of fashion and markdown pricing," American Economic Review, 78, 936-53.

Pesendorfer, M. (2002): "Retail Sales: A Study of Pricing Behavior in Supermarkets," Journal of Business, 75, 33-66.

Petrin, A. (2002): "Quantifying the Benefits on New Products: The Case of the Minivan," Journal of Political Economy, 110, 705-729.

RAmeY, V. A., And D. J. VINE (forthcoming): "Declining Volatility in the U.S. Automobile Industry," American Economic Review.

Rust, J. (1987): “Optimal Replacement of GMC Bus Engines: An Empirical Model of Harold Zurcher," Econometrica, 55, 999-1033.

SChIRALDI, P. (2006): “Automobile Replacement: a Dynamic Structural Approach," manuscript.

Slade, M. E. (1998): "Optimal Pricing with costly adjustment: Evidence from retail-grocery prices," Review of Economic Studies, 65, 87-107.

Sobel, J. (1991): "Durable Goods Monopoly with Entry of New Consumers," Econometrica, $59,1455-1485$.

Song, I., And P. Chintagunta (2003): "A micromodel of new product adoption with heterogenous and forward-looking consumers: An application to the digital camera category," Quantitative Marketing and Economics, 1, 371-407.

Stokey, N. (1979): "Intertemporal Price Discrimination," Quarterly Journal of Economics, 93, 355-371. 
Zettelmeyer, F., F. S. Morton, And J. Silva-Risso (2003): "Inventory fluctuations and price discrimination: The determinants of price variation in car retailing," manuscript. 